\title{
Future of Research in Family Medicine: Where To From Here?
}

\author{
Carol P. Herbert, MD, CCFP, FCFP, \\ FRCP (Glasgow)
}

Faculty of Medicine \& Dentistry, University of Western Ontario, London, Ontario, Canada
Conflict of interest: none reported

\section{CORRESPONDING AUTHOR}

Carol P. Herbert, MD Faculty of Medicine \& Dentistry

University of Western Ontario

Health Sciences Addition

London, Ontario N6A 5C1

carol.herbert@fmd.uwo.ca

\begin{abstract}
Desired research outcomes in family medicine vary according to the developmental stage of the discipline and the context of practice. Several milestones in the evolution of family practice research worldwide have been achieved. Now family medicine researchers face the challenge of discovering how evidence-based primary health care can be delivered in a sustainable way to individuals within communities. To advance family medicine research, we must ensure that trainees have a positive research attitude, develop academic clinician-researchers, lobby for primary care research funding, support practitioners who wish to do research in their own practices, sustain practice-based research networks, and study important questions.
\end{abstract}

Ann Fam Med 2004;2(Suppl 2):S60-S64. DOI: 10.1370/afm.151.

\section{INTRODUCTION}

W hy is it that we have had such a hard time as a discipline in developing a research base and a base of researchers? We hearken back to our forebears Jenner, Mackenzie, and Pickles, who did clinical and epidemiological research_-providing careful and accurate observations over time. Yet even Mackenzie said, "About 1883, I resolved to do a series of careful observations, entirely for my own improvement, never dreaming of research, for I was under the prevalent belief that medical research could only be undertaken in a laboratory or ... in a hospital."1 Our self-image as family physicians has not included researcher as a normative descriptor. The family medicine researcher has been seen as an outlier, slightly odd, unclear as to her motivation (clearly not financial), useful within the academy where research is expected, but of uncertain relevance in community practice.

One defining characteristic of an academic discipline is a distinct body of knowledge that is advanced by scholarship and can be taught to practitioners in the discipline. We have struggled to define what scholarship should be in our discipline. This conference will result in a document that states the position of research in family medicine worldwide, ways to build global scientific capacity and research infrastructure, and possibilities to promote family medicine research around the world. The 6 areas for which recommendations will be derived are as follows:

1. A description of the research domain of family medicine

2. How to build research capacity

3. How to create and allocate research funds for family medicine

4. Assuring the quality of research

5. Research and general practice development in developing countries

6. The role of Wonca in promoting research in family medicine worldwide

To set the stage for the conference, I will consider the desired outcomes of research in the practice-based discipline of family medicine within a historical context and then suggest how we can best achieve those outcomes, that is, where to from here? 
It is evident that desired outcomes vary according to the developmental stage of the discipline and to the context of practice at the time. Thus, for example, in the 1960s, as family medicine emerged as a formal discipline in North America, the emphasis was on education of physicians who would care for the person, who would restore the idea of context and relations in medicine. Our energies were directed inward, toward justifying ourselves, toward creating our roles, and toward attempting to solve our patients' medical problems. ${ }^{2}$ Little attention was directed toward research.

As early as 1966, however, Ian McWhinney identified the family medicine research arena as follows: evaluation of signs, symptoms, and diagnostic tests; epidemiology of illness; physical and mental development; behavior; and social influence. ${ }^{3}$ During the next decade, others emphasized clinical strategies, health care services, educational methods, and behavioral medicine, ${ }^{4,5}$ the family, ${ }^{6,7}$ the spectrum of disciplines from biomedical science to social science, the continuum from pathogenesis of disease to health services and public policy, and a range of approaches from individual research to multicentered trials. ${ }^{8}$

Similar evolution of the research agenda was occurring in Europe during this period, with early important work by such general practitioners as Huygens in the Netherlands, who studied the family and illness by using his own office records, and Clifford Kay at the Manchester Unit in the United Kingdom, who directed the world's largest collective research study using general practitioner's records. It is important to note that the UK College of General Practitioners recognized the need to concentrate on research from the college's inception in 1952. Three obstacles were identified: professional isolation, lack of skills and experience in research, and the lack of presence of general practice in the universities. The world's first chair of general practice was established at the University of Edinburgh in 1963, a landmark in the development of academic family medicine. Meanwhile the college supported a number of research units since 1953, with 2 research units at present: the Birmingham Unit and the Centre for Primary care Research and Epidemiology in Aberdeen (the successor to the Manchester Unit). ${ }^{9}$

In 1982, The Study Group on Family Medicine Research ${ }^{10}$ in the United States made a number of recommendations that sound contemporary and that transcend national boundaries. They pointed out particular areas where family medicine could make special contributions, including health and disturbed health, health care delivery, and medical education. They recommended to practitioners and teachers that practicing family physicians conduct research in their own practices, that family medicine teachers conduct research and assist practice-based researchers, that practitioners and teachers recognize the importance of research and apply the results of research. They recommended to academic units that faculty should be given protected time, that learners should have research elective time, and that family medicine research centers should be developed as a resource to teachers and practitioners. They also called for family medicine professional organizations to raise funds to support research, provide forums, and communicate the research activities and needs of family medicine to other constituencies. ${ }^{11}$

In 1991, Culpepper ${ }^{12}$ suggested 2 major research themes: (1) questions directly applicable to practice, and (2) questions that integrate biological changes with individual perceptions, feelings, and values and with social interaction. He identified 3 areas of integrative research as interactions between patient and physician, interactions between the family and individual health, and investigation of effects of the community on individual health. He defined family medicine research as follows, pointing out that this definition also could serve for primary care research:

Family medicine research addresses the need for knowledge by family physicians so they may better manage their patients, their families, and their practices and fulfill their health care role at the community level. Further, family medicine research particularly seeks to answer questions which require the family practice setting or the relationship among family physician, patient, family, and community. It investigates issues from the family physician's and the patient's perspectives. ${ }^{13}$

Culpepper argued that while there was still need for basic descriptive and exploratory work, including natural history studies in primary care settings, the discipline must become theory based, with investigations grounded in the Institute of Medicine definition of primary care: "the provision of integrated, accessible, health care services by clinicians that are accountable for addressing a large majority of personal health-care needs, developing a sustained partnership with patients, and practicing within the context of family and community."13

In 2000, Roger Jones ${ }^{14}$ drew similar conclusions when he wrote that the "ends" of primary care research have to be the improvement of quality, effectiveness, and cost-effectiveness of primary care. The research questions need to spring from the realities of providing primary care services in communities.

In a paper presented at the Keystone III Conference, Stange, Miller, and McWhinney ${ }^{15}$ placed the research agenda for family medicine in a theoretical context when they argued that we have a special approach to building knowledge, "a multi-method transdisciplinary participa- 
tory approach to create knowledge that retains its connections with its meaning and context and therefore is readily translatable into practice."

\section{WHAT ARE THE DESIRED OUTCOMES IN 2003?}

So where are we in 2003? We have developed models for research networks of practices; promoted evidencebased medicine ${ }_{i}$ created a theory of patient-centered medicine; and changed practice by our work in areas such as clinical outcomes, mental health, and prevention. We have come a long way, as evidenced by the world literature in family medicine and the contributions of family medicine and general practice researchers in the general literature.

At the same time, with patterns of primary care in some jurisdictions changing so that family physicians are giving up maternity care, hospital work, and care of the dying to specialists in those fields, we are challenged as a practice-based discipline to define our scope of practice. In countries such as Canada and the United States, we risk becoming restricted service physicians-medical technicians du jour who provide episodic care for common illnesses by algorithm, 9-to5ers, docs-in-a-box ${ }^{16}$ to patients whose names we do not know. ${ }^{17}$ Yet the reality of physician shortages forces patients to use walk-in clinics and reinforces the choice of some primary care physicians to provide restrictedbut at least accessible-office care only.

Meanwhile, it is heartening to see the growth of family medicine worldwide, in central and eastern Europe, in Asia, and in Central and South America, as governments recognize the centrality of a robust system of primary care to the health of nations. Family medicine leaders in countries where family medicine has only recently emerged as a model for delivery of health care to the population point out that their energies, as in the 1960 s in North America, are taken up with education and clinical care of large numbers of patients.

In all countries we have a special obligation to conduct trials to determine how evidence-based health care services can be delivered in a sustainable way to individuals within communities and within the definition of primary care. This health services and health care research matters greatly to health care and health outcomes. In that context, the importance of primary care research networks cannot be overemphasized. We can and must build upon the early observational and descriptive work of family medicine research pioneers by crafting carefully designed experiments that can be translated into changed and improved practice. Can we develop innovative care models to make quality care possible?

Particular communities demand our attention. Bar- bara Starfield speaks of the need to improve equity in health, an agenda that reminds us of the roots of family medicine. ${ }^{18}$ We have a role to play in studying differences in practice, experience, and outcome for subgroups characterized by different ages, ethnicity, gender, and socioeconomic status, including income, education, and occupation. We must attend to decision making by patients and physicians in respect to health promotion and preventive behaviors, use of medications, and employment of complementary and alternative medicine. We must study ethical issues in primary care, from genetic testing to rationing of care. As we go forward, there is a special place for primary care researchers who work at the interface with communities, understand the special ethical concerns of community-based research, have skills and experience in participatory action research, and can incorporate ethnography and other qualitative methods to enable thick and rich description. ${ }^{19}$

\section{HOW DO WE ACHIEVE THE DESIRED RESEARCH OUTCOMES?}

John Howie ${ }^{20}$ says "those who deliver health services work in a culture that values and rewards doing rather than conceptualizing. Many have become general practitioners because they have rejected the apparently research-centered values of teaching hospitals and their staff." The counterpoint to that position is articulated by Murray Tilyard"1 as, "We do research because we need practical answers to practical questions."

To engage practicing physicians - and our studentsin research, we must seek answers to their questions that will change understanding of health and illness, management and intervention, and ultimately, health outcomes. An example of theoretically grounded research of this sort is that of Stewart and colleagues, which shows improved outcomes with application of the patient-centered clinical method. ${ }^{22}$

If we are to have a major impact on understanding what is "best practice" in primary care, on disseminating and implementing evidence, and on changing health outcomes, we have 6 tasks. ${ }^{11}$ First, we must ensure that our trainees will have a positive research attitude. We must model at all times a questioning approach to our work-not only in the academic center but also in real practice where students see role models whom they will emulate. All of our teachers must recognize the importance of asking and answering the questions of primary care and general practice in our settings with patients that look like our patients. We must teach from our literature, pointing out the knowledge we have built, both theoretical, eg, the patient-centered model, and practical, eg, the management of spontaneous abortion. 
We must demonstrate critical thinking and a commitment to evidence-based medicine, where the evidence that counts is not only the randomized controlled trial but also the particularities of the individual in their social context. We must support resident projects and create educational and career paths to encourage young investigators.

Second, we must develop clinician-researchers. Carole Bland and Constance Schmitz ${ }^{23}$ identified qualities of successful researchers. They noted that early scholarly interest with publications in the first 5 years predicted later output. They also defined the role of mentors as critical to development. Mentors can be found locally, nationally, or even internationally. Within our university departments, we must proselytize research career paths and make them possible, providing protected time and assistance with grant preparation. We also need education for mid-career clinicians who want to do research-as primary investigators, participants in research, or contributors of questions.

Third, we must continue to lobby our funding bodies to devote funding to primary care research, to include primary care researchers on grant panels, and to build research capacity. Only a small percentage of national research funding in any country goes to primary care research. Even so, capacity-building has become a major activity for the North American Primary Care Research Group (NAPCRG) during the last few years, with consequent early successes seen in new National Institutes of Health grants to primary care researchers. Meanwhile, both the National Health Service and the Medical Research Council in the United Kingdom have defined the major need for building research capacity in primary care research. ${ }^{24,25}$

Elsewhere in Europe, countries have been evolving their primary care research in relation to their health care system. In Spain, a reform process in primary care began in 1985 with an evolving public health service staffed by full-time salaried physicians who work for primary care centers. ${ }^{26}$ Research in the new specialty of family medicine has been focused on demonstrating the effectiveness of the primary health care approach, with most of the primary care research carried out in government health centers. In all European countries, while early primary care research was mostly descriptive, ${ }^{27,28}$ more complex studies are being published lately. In Australia rapid development of family medicine research during the last decade was kick-started by a major federal investment in innovation at the practice level.

Fourth, we must support and nurture physicians who may be stimulated to do clinical research in their own practices in the tradition of Pickles, McKenzie, and McWhinney. While most family medicine researchers with protected time will be in academic departments, a precious few private practicing physicians will beaver away in their offices and community settings, asking and answering important questions, obtaining funding as needed, and borrowing time from Peter's practice and family to pay researcher Paul. McWhinney reminds us that we should not lose sight of the special opportunity that a general physician has to observe, record, classify, and analyze day-to-day clinical experiences for long periods in that tradition. ${ }^{29}$

Fifth, we must sustain our practice-based research networks. ${ }^{30}$ Indeed, Kernick, Stead, and Dixon, British general practitioners, argue that primary care groups should be the locus for health services research-outside academic centers and university departments. ${ }^{31}$ University-based primary care researchers must be well connected to community-based physicians and other health care professionals who are delivering health care services to patients in communities if their questions are to remain relevant.

Sixth, we must study what matters. While we acknowledge the dilemma of academe, where promotion and tenure are time-limited processes with prescribed steps to the dance, we must find ways to support longitudinal research. We must examine major drivers of cost in diagnosis and treatment, prevalent and serious illnesses, fundamentals of how decisions get made by physicians and patients, and the impact of health and illness on patients and providers. We need to interact with our communities of patients as partners in research.

I look forward to other papers that will delineate directions to be taken worldwide to advance research in family medicine.

To read or post commentaries in response to this article, see it online at http://www.annfammed.org/cgi/content/full/2/suppl_2/S60.

Key words: Family practice; research

A version of this paper was presented at the Wonca Research Conference, Kingston, Ontario, Canada, March 8-11, 2003.

\section{References}

1. Mackenzie Sir J. Symptoms and Their Interpretation. 4th ed. London: Shaw and Sons; 1921

2. Rodnick, JE. Research in family medicine: counterculture continued. Fam Med. 1987; 19:251-252, 305-307.

3. McWhinney IR. General practice as an academic discipline: Reflections after a visit to the United States. Lancet. 1966;1:419-423.

4. Geyman JP. Toward a research base in family practice. J Fam Pract. 1975;2:3.

5. Wood M, Stewart W, Brown TC. Research in family medicine. J Fam Pract. 1977;5:62-77.

6. Shank JC. A taxonomy for research. Fam Med Teacher. 1980;12:22-23. 
7. Medalie JH, Kitson GC, Zyzanski SJ. A family epidemiological model: a practice and research concept for family medicine. J Fam Pract. 1981;12:79-87.

8. Phillips TJ. Research considerations for the family physician. J Fam Pract. 1978;7:121-128.

9. Carter $\mathrm{YH}$. Research in general practice: climbing the mountain. In: Carter YH, Elwyn G, Hungin P, eds. General Practitioner Research at the Millennium: a Perspective From the RCGP. London, UK: Royal College of General Practice; 2000.

10. Parkerson GR, Barr DM, Bass M, et al. Meeting the challenge of research in family medicine: report of the study group on family medicine research. J Fam Pract. 1982;14:105-113.

11. Herbert CP. Research in family medicine and general practice: are we there yet? Br J Gen Pract. 2002;52:443-446.

12. Culpepper L. Family medicine research: major needs. Fam Med. 1991;23:10-14.

13. Donaldson M, Yordy K, Vanselow N. Primary Care: America's Health in a New Era. Washington, DC: Institute of Medicine, National Academies Press; 1996.

14. Jones R. Primary care research: ends and means. Fam Pract. 2000; 17:1-4.

15. Stange KC, Miller WL, McWhinney I. What is the science base of family practice and how will it be developed? Fam Med. 2001;33: 286-297.

16. Herbert CP. To know your patient's name. Can Fam Physician. 1998; 44:16-18

17. Herbert CP. The future of family medicine: research. J Fam Pract. 2001;50:582-583.

18. Starfield B. Improving equity in health: a research agenda. Int J Health Serv. 2001;31:545-566.
19. Macaulay AC, Commanda LE, Freeman WL, et al. Participatory research maximises community and lay involvement. BMJ. 1999;319: 774-778.

20. Howie JGR. Research in general practice: international problemsinternational solutions. Fam Pract. 1994;11:351-357.

21. Tilyard M, Dovey S. Research in general practice or general practice research. New Zealand Med J. 2000;113:150-151.

22. Stewart M, Brown JB, Weston WW, McWhinney IR, McWilliam CL, Freeman TR. Patient-Centred Medicine: Transforming the Clinical Method. Thousand Oaks, Calif: Sage Publications; 1995.

23. Bland CL, Schmitz CC. Characteristics of the successful researcher and implications for faculty development. J Med Educ. 1986;61:22-31.

24. Medical Research Council. Primary Health Care. Topic Review. London, UK: Medical Research Council; 1997.

25. Mant D. National Working Group on RED in Primary Care: Final Report. London: NHS Executive; 1997.

26. Foldspang A, Hvidman L. Danish primary health care research 1950-1980. Scand J Prim Health Care. 1985;3:183-188

27. Haglund BJA. Research and development work in primary health care in Sweden. Scand J Prim Health Care. 1985;3:107-112.

28. Gene-Badia J, Jimenez-Villa J, Martin-Zurro A. Family practice research in Spain. Fam Pract Res J. 1993;13:7-15.

29. MCWhinney IR. Why are we doing so little clinical research? Part 1. Clinical descriptive research. Can Fam Phys. 2001;47:1701-1702.

30. Green L. Putting practice into research: a 20-year perspective, Fam Med. 2000;32:396-397.

31. Kernick D, Stead J, Dixon M. Moving the research agenda to where it matters. BMJ. 1999;319:206-207. 